\title{
Role of tissue typing on preserved nerve allografts in dogs
}

\author{
R. S I N G H, K. M E C H E L S E, A N D S. S T E F A N K O \\ From the Departments of Neurosurgery, Electroneurology, and Neuropathology, Academisch \\ Ziekenhuis Rotterdam-Dijkzigt, Erasmus University, Rotterdam, the Netherlands
}

SUMMARY Histocompatibility seems to play an important role in the regeneration of nerve allografts. Compatible tissue typed nerve allografts behave more like autografts and are, therefore, more readily accepted by the host tissue without producing evident tissue rejection. The influence of histocompatibility difference becomes more marked if the graft is longer than $30-40 \mathrm{~mm}$. Irradiation as a means of reducing the immune reaction of the nerve allografts does not seem to have any beneficial effect along with tissue typing. Preservation of nerve grafts at $-70^{\circ} \mathrm{C}$ does not have any untoward effect.

During the last decades, autotransplantation to bridge peripheral nerve defects has become a method of choice in most clinics. Usually cable grafts are used of expendable sensory nerves and sutured interfascicularly as advocated by Millesi (1972). This technique minimises the tissue rejection problem, and good results have been reported by Millesi (1972), and Samii and Kahl (1972). However, the following specifications for an ideal transplant remain unfulfilled:

$a$. the normal neurolemmal system consisting of a specific funicular arrangement (Sunderland, 1968) of the parent nerve, which seems to be quite important in achieving optimal qualitative and quantitative end results, is not replaced.

$b$. the thickness and number of the transplanted nerve segments are seldom the same as in the original nerve involved.

c. the available sensory nerves may be too short to bridge a large gap in a thick nerve or gaps of more than one nerve at the same time.

$d$. the sacrifice of the donated sensory nerve might sometimes produce some neurological deficit in the donor.

Gutman and Sanders (1943) and Seddon and Holmes (1944), in animal and human experiments with homografts concluded that a graft of about $30 \mathrm{~mm}$ long was the limit which could survive. Longer grafts showed diffuse inflammatory reaction, leading to less than optimal blood supply and consequent fibrosis of the entire graft. This reaction was attributed to the immune reaction on the part of the host tissue, the severity and Accepted 13 January 1977 rapidity of which varied according to the genetic relationship between donor and host.

Since that time many attempts have been made to minimise the immunological reaction in laboratory and in clinical applications. Das Gupta (1967), with electronmicroscope studies, showed that allogenous nerve when transplanted is subjected to a rejection process similar to that which occurs in other tissues. Attempts to reduce donor nerve antigenicity by irradiation (Marmor, 1967) have produced disappointing clinical results, despite earlier promising experimental studies (Marmor, 1964). Pollard and Fitzpatrick (1973) have described the mechanisms whereby the immune process hinders regeneration. Improved regeneration has been demonstrated through allografts in experiments with animals treated with immunosuppressive agents (Pollard et al., 1973).

The aim of the present study was to determine the role of tissue typing on regeneration through preserved peripheral nerve allografts.

\section{Material and methods}

Thirty-six beagle dogs were tissue typed using the major histocompatibility complex system (Ceppelini et al., 1967). Peroneal nerve was removed and preserved in tissue culture medium 96 in triple sealed plastic bags, at a constant minimal temperature of $-70^{\circ} \mathrm{C}$ under sterile conditions, for a period of four to six weeks, before implantation into other dogs. The standard microsurgical technique was applied using $\times 16$ magnification and $10 \times 0$ atraumatic monofilament nylon. Three 
series of experiments were carried out with different types of peroneal nerve transplants, in each of which there were six compatible and six incompatible dogs.

Series 1: $40 \mathrm{~mm}$ peroneal nerve transplant submitted to radiation at dry ice temperature (Marmor, 1964).

Series 2: $40 \mathrm{~mm}$ peroneal nerve transplant-no irradiation.

Series 3: $70 \mathrm{~mm}$ peroneal nerve transplant-no irradiation.

About seven to eight months after the transplantation, the nerve was re-exposed, the reaction to direct electric stimulation recorded, and the nerve conduction velocity determined, with animals under general anaesthesia and using bipolar platinum electrodes. Four electrodes were placed at fixed distances of $20 \mathrm{~mm}$ along the nerve, the first proximal to and the last distal to the graft. The compound action potential of the anterior tibial muscle was recorded through a concentric needle electrode. The nerve was stimulated supramaximally with a square wave of $0.3 \mathrm{~ms}$ duration. The temperature of the nerve ranged between $27^{\circ}-30^{\circ} \mathrm{C}$. The maximum conduction velocity of the graft was estimated from the latency of responses of the anterior tibial muscle from stimuli at the proximal and distal stimulating points, and the conduction distance. In normal dogs the maximum conduction velocity of the peroneal major nerves ranged from $30 \mathrm{~m} / \mathrm{s}$ to $50 \mathrm{~m} / \mathrm{s}$.

According to the nerve conduction velocity, results were grouped into four grades:

Grade I normal conduction velocity

Grade II reduced conduction velocity $>30 \mathrm{~m} / \mathrm{s}$ $20-30 \mathrm{~m} / \mathrm{s}$

Grade III markedly reduced conduction velocity

Grade IV no response.

$15-19 \mathrm{~m} / \mathrm{s}$

The transplanted nerve along with $10 \mathrm{~mm}$ of proximal and distal end of the host nerve was removed for histological study. Longitudinal sections at proximal and distal segments of the host nerve were prepared with specific stains. To evaluate the degree of axonal regeneration, the Bodian method was employed. Kluever's method was used to visualise the late stage of myelin regeneration. Special attention was paid to qualitative pictures of the nerve sheaths. The Van Gieson and haematoxylin eosin method was used to visualise the connective tissue.

To make differential evaluation easier, care was taken to obtain nerve sections at the same level in relation to proximal and distal nerve suture sites. A diagramatic representation shows the exact site of different longitudinal and transverse sections in relation to the transplant (Fig. 1).
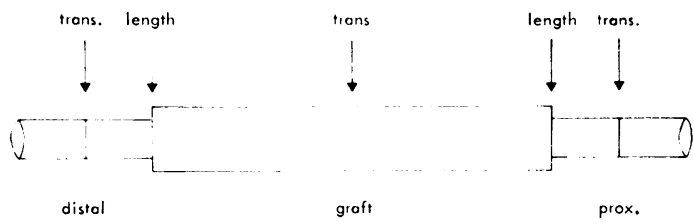

Fig. 1 Diagram of sites of longitudinal and transverse section (trans).

The quantitative and qualitative histological findings were grouped into four grades:

Grade I (Fig. 2a, b, c) good regeneration with beginning of myelinisation; parallel bundles of nerve fibres; no fibrosis; no inflammatory reaction.

Grade II (Fig. 3a, b, c) good regeneration; little irregularity in parallel run of the nerve fibre bundles; slight fibrosis; no inflammatory reaction. Grade III (Fig. 4a, b, c) incomplete regeneration; slight interlacing of the nerve fibres; evident fibrosis; slight inflammatory reaction.

Grade IV (Fig. 5a, b, c) poor regeneration; marked interlacing of nerve fibres; extensive fibrosis; evident inflammatory reaction.

For both EMG and histology, grade I was interpreted as the best and grade IV as the worst, grades II and III being intermediate. Results thus obtained were subjected to statistical analysis using a nonparametric ranking procedure (Wilcoxon's two sample test) for comparison of the different groups.

The neurological examination of the dog, which in itself is not very reliable and could bias the interpretation of the end results, was not taken into consideration when summarising the end results.

\section{Results}

\section{SERIES 1}

(40 $\mathrm{mm}$ grafts, submitted to radiation)

In the compatible group nerve conduction velocity was normal in three cases and reduced in two. One dog was lost during the follow-up period. In the non-compatible group no response was recorded in three cases, markedly reduced conduction velocity in two, and reduced conduction velocity in one case only.

Differences in the results of these two groups are of statistical significance (Fig. 6, $p<0.01$ ). On histological analysis four of the compatible group were graded as grade I and one grade II, in 


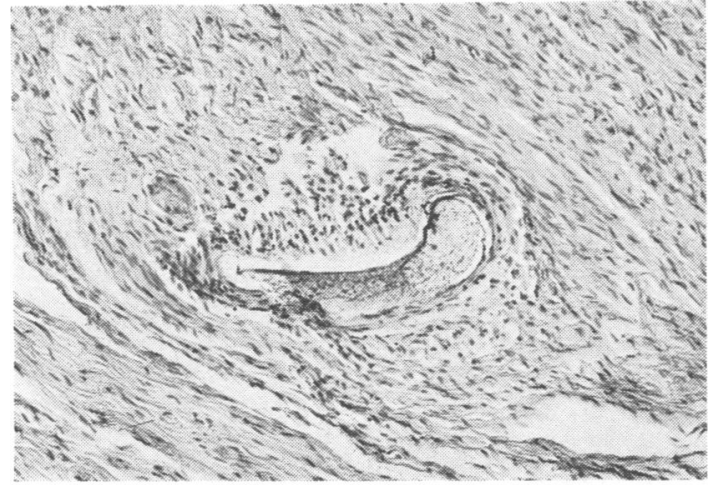

(a)

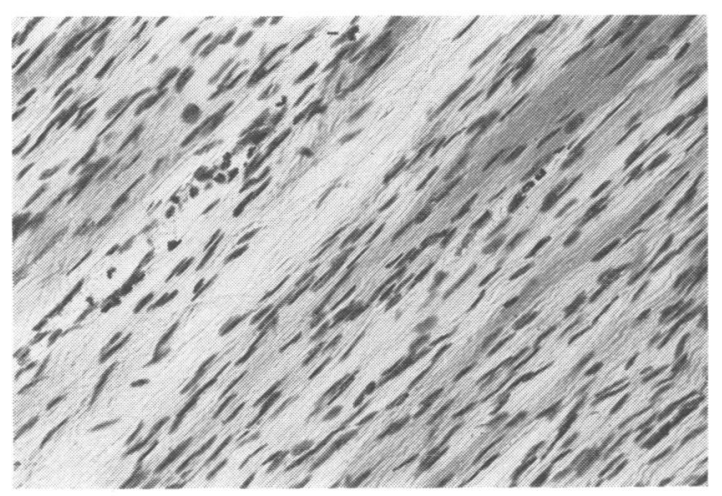

(b)

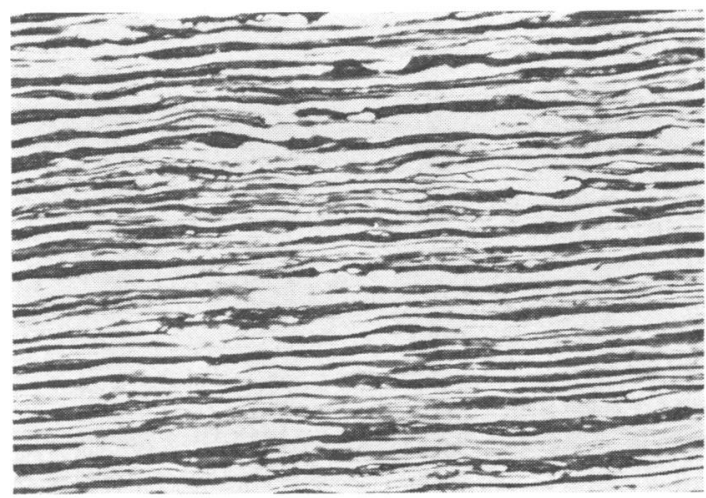

(c)

Fig. 2 Grade I of histological grading. (a) Site of nerve suture. Slight lymphocytic reaction close to the suture. $(H \& E \times 235)$. (b) Distal nerve segment. Regular course of Bunger-Hanke's strands (proliferation of Schwann cells). $(H \& E \times 380)$. (c) Distal nerve segment. (Bielschowsky stain). Dense texture of regenerated fibres $(\times 380)$.

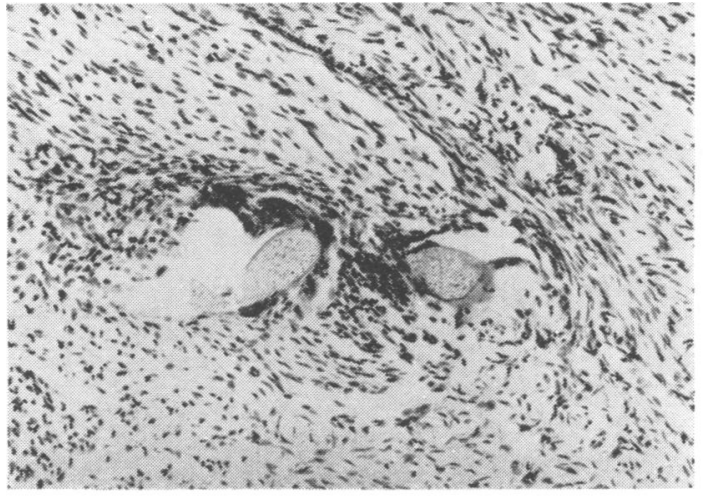

(a)

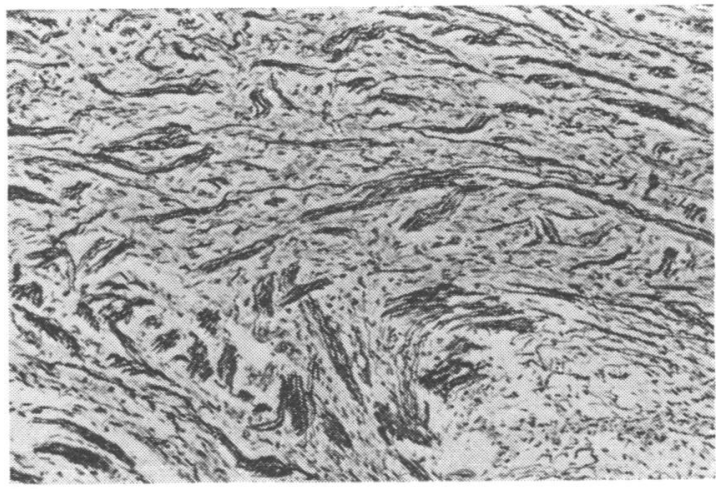

(b)

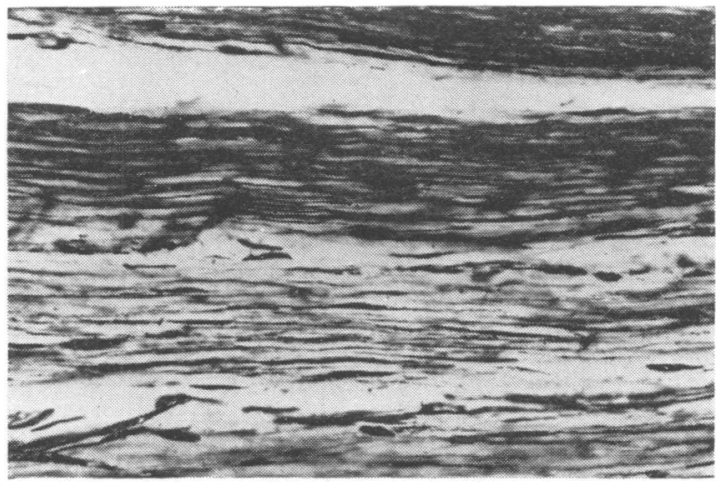

(c)

Fig. 3 Grade II of histo!ogical grading. (a) Site of nerve suture. Remnants of suture and polymorph inflammatory reaction with foreign body giant cells. (H\& $E \times 380)$. (b) Distal nerve segment. Slight irregularity of nerve fibre bundles. (Bielschowsky $\times 235$ ). (c) Distal nerve segment. Longitudinal course of nerve fibres with uneven tcxture of bundles. (Bielschowsky $\times 235$ ). 


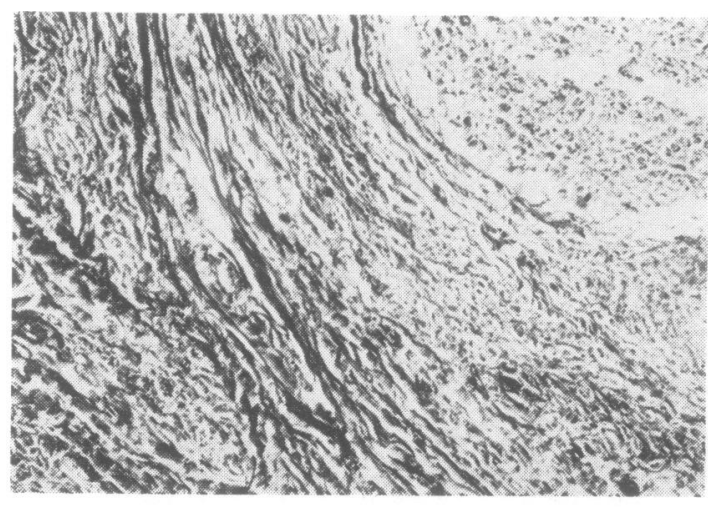

(a)

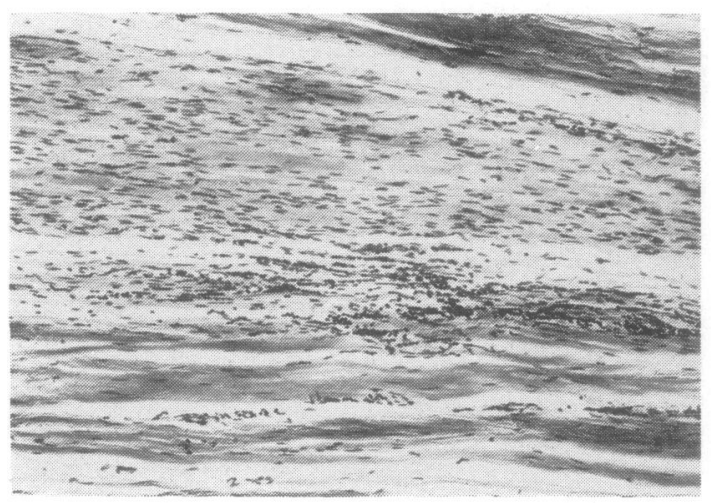

(b)

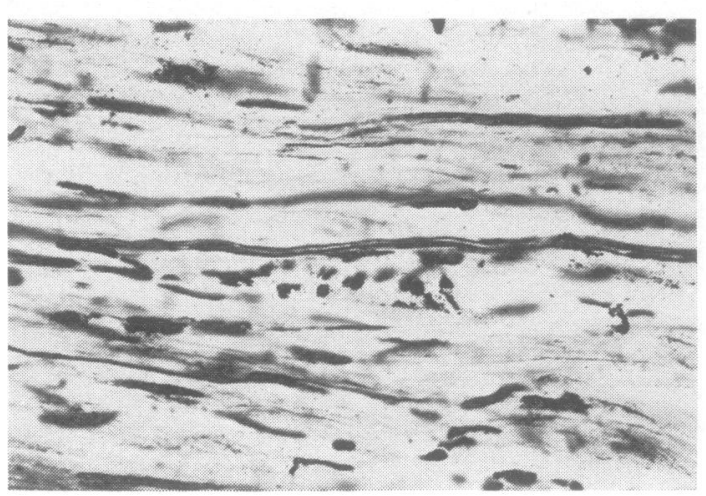

(c)

Fig. 4 Grade III of histological grading. (a) Site of nerve suture. Slight interlacing of the nerve fibres. (Van Gieson $\times 235$ ). (b) Distal nerve segment. Inflammatory reaction in epineurium $(H \& E \times 235)$. (c) Distal nerve segment. Uneven thickness of the fibres and thin density. (Bielschowsky $\times 280$ ).

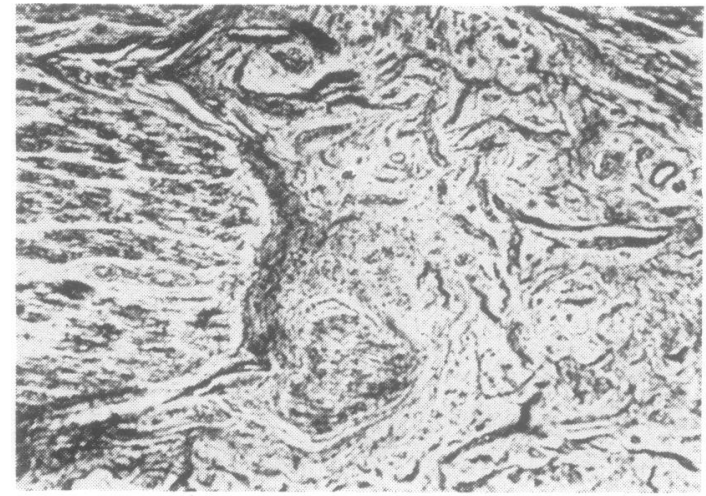

(a)

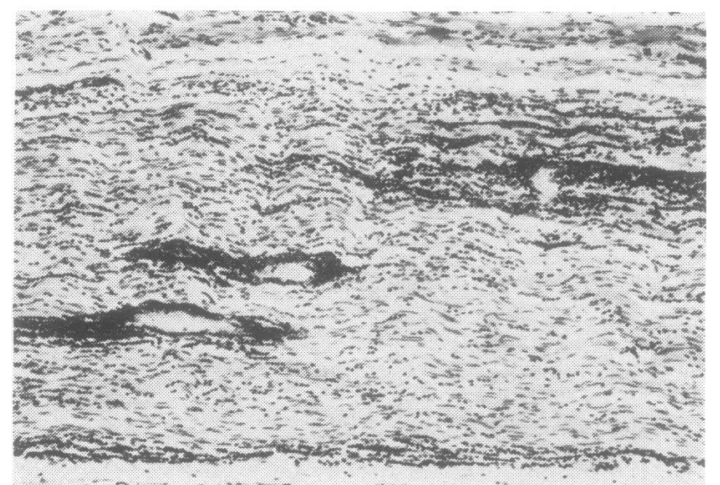

(b)

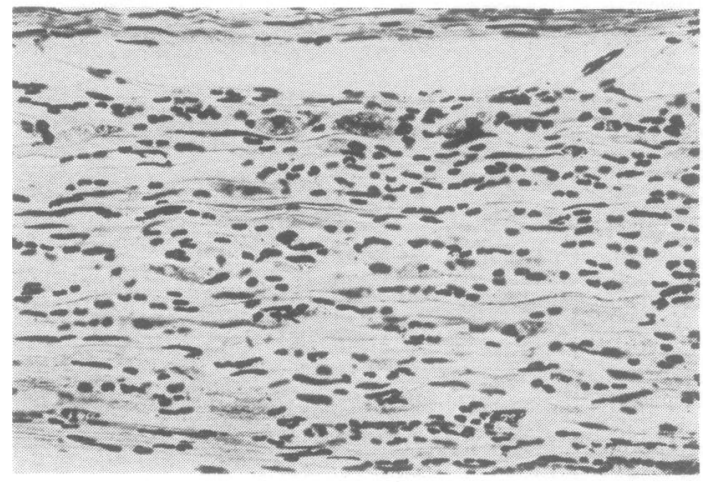

(c)

Fig. 5 Grade IV of histological grading. (a) Site of nerve suture. Marked interlacing of nerve fibres. Considerable proliferation of connective tissue and aberrant fibres. (Van Gieson $\times 235$ ). (b) Distal nerve segment. Diffuse inflammatory reaction in epi- and peri-neurium. ( $H \& E \times 235)$. (c) Distal nerve segment. Poor regeneration (Bielschowsky $\times 380$ ). 


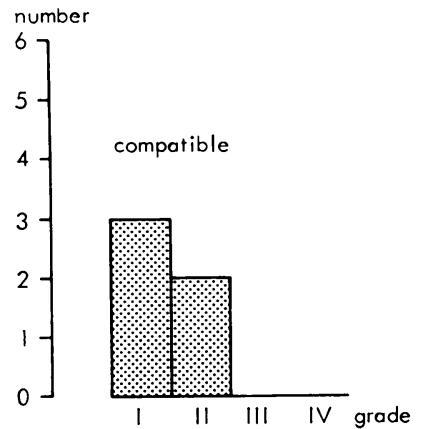

non-compatible

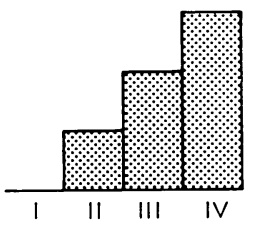

Fig. 6 EMG radiation +deep freezing $40 \mathrm{~mm} \mathrm{P}<0.01$.

contrast to the non-compatible group where all six were graded III and IV. This difference is also statistically significant (Fig. 7, $\mathrm{P}<0.01$ ).

These results indicate that better regeneration was found in the compatible group of dogs than in the non-compatible. On histological examination there was marked foreign body and inflammatory reaction in the non-compatible group while in the compatible group a more normal pattern of regeneration, with minimal foreign body reaction was found.

Preservation of the nerves under these conditions seems to have no adverse effect on the regeneration of the nerve grafts. However, it is difficult to estimate by this examination how far irradiation had been responsible for diminishing the immune reaction of these transplanted nerve grafts. For this reason series 2 was carried out.

\section{SERIES 2}

(40 $\mathrm{mm}$ grafts without irradiation)

In the compatible group nerve conduction velocity was normal in two cases and reduced in four. In the non-compatible group a normal conduction velocity was not recorded in any case. Reduced
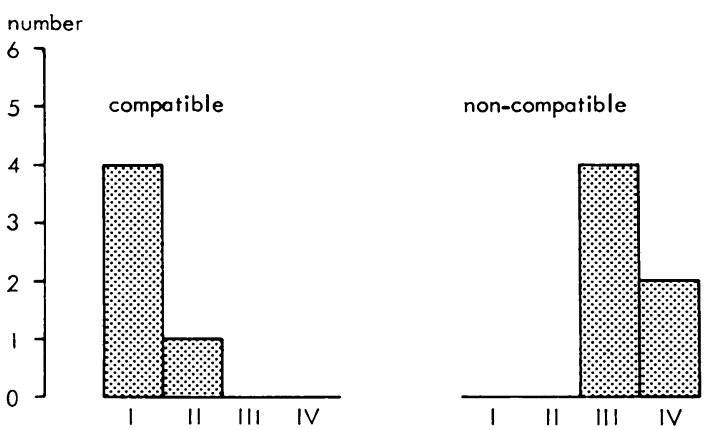

Fig. 7 Histology radiation+deep freezing $40 \mathrm{~mm}$ $\mathrm{P}<0.01$. nerve conduction velocity was recorded in four, markedly reduced in one and no response at all in one case. On statistical analysis the difference in these two groups, however, is not significant (Fig. $8, \mathrm{P}>0.05$ ). On histological study, among the
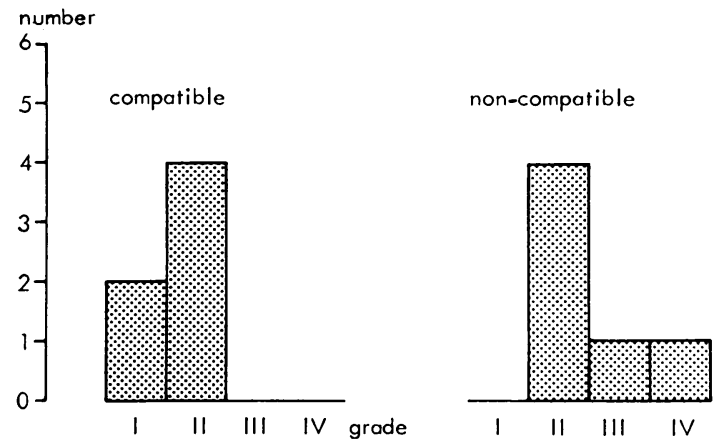

Fig. $8 \quad$ EMG deep freezing $40 \mathrm{~mm} \mathrm{P}>0.05$.

compatible group four showed regeneration with a very normal pattern (grade I), and one showed grade II. In one case the suture line was found to be broken (probably due to technical error), and this was graded as IV. In the non-compatible group none was good enough to be included in grade I, two were in grade II, three in grade III, and one in grade IV. Thus here also the results in the compatible group seem a little better than in the non-compatible group, although some of the grafts in the non-compatible series did show some definite signs of regeneration. Better qualitative and quantitative regeneration along with minimal foreign body and inflammatory reaction was seen in compatible cases compared with the non-compatible cases. The histological difference between these groups is of statistical significance only if the case where the suture line was found to be broken is not taken into consideration. Otherwise the difference is not significant (Fig. 9, $\mathrm{P}>0.05$ ). There
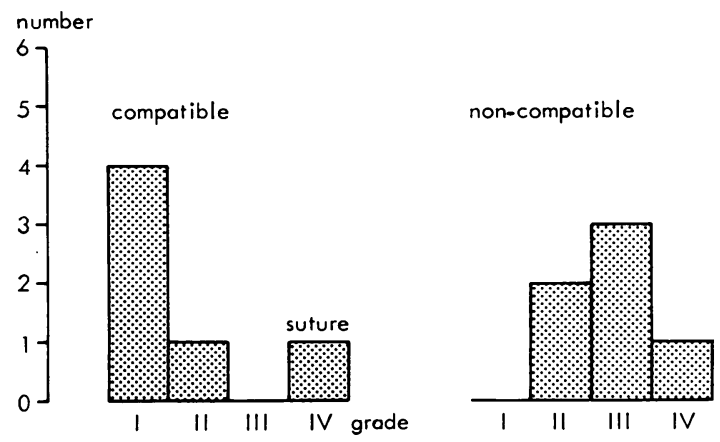

Fig. 9 Histology deep freezing $40 \mathrm{~mm}$ p $>0.05$. 
is no significant difference $(P>0.05)$ in conductivity or histological grading of these $40 \mathrm{~mm}$ grafts with and without radiation in compatible and non-compatible series. However, a better type of regeneration with less foreign body and inflammatory reaction was found in cases where no radiation was carried out, so radiation appears to be without additional advantage.

\section{SERIES 3}

(70 $\mathrm{mm}$ grafts without irradiation)

On EMG examination in the compatible group, five showed normal nerve conduction velocity, while the one where the suture line was found to be broken registered no response at all. This is in marked contrast to the non-compatible group where no response could be recorded in three cases and only a response with markedly reduced conduction velocity in the remaining three cases. The difference in these results is statistically significant (Fig. 10, $\mathrm{p}<0.05$ ).

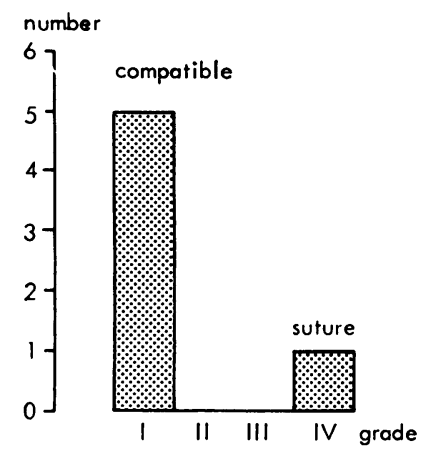

non-compatible

Fig. 10 EMG deep freezing $70 \mathrm{~mm} \mathrm{P}<0.05$.

On histological examination four from the compatible group were grade I and one grade II. The case with the broken suture line was grade IV. In the non-compatible group all showed marked inflammatory, foreign body reaction, and fibrosis without any normal regeneration, and are thus included in grade IV. This difference between the two groups is also of statistical significance (Fig. 11, $\mathrm{P}<0.05$ ). Comparing these EMG and histological results with those of $40 \mathrm{~mm}$ grafts without radiation, the difference in the non-compatible group is statistically significant $(P<0.05)$.

\section{Discussion}

These results support the view of Seddon and Holmes (1944) and Spurling et al. (1945) that some of the grafts of about $30 \mathrm{~mm}$ length might show some signs of regeneration in spite of all the odds.

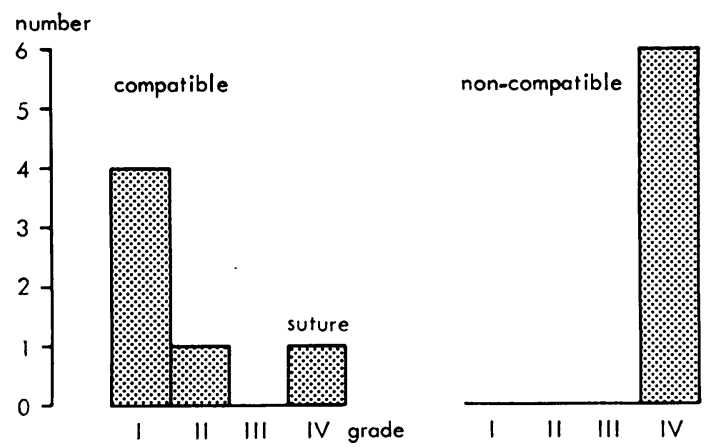

Fig. 11 Histology deep freezing $70 \mathrm{~mm} \mathrm{P}<0.05$.

Some vascularisation of the graft could take place from either end of the host nerve. Longer grafts may have difficulty in surviving under adverse conditions. Ducker and Hayes (1970) supforted these views by their experimental study in chimpanzees, and commented that irradiated nerve grafts are unlikely to be succesful when longer than $40 \mathrm{~mm}$.

Comparison of individual histological and electromyographic gradings (Table) showed that a grading agreement exists in 28 cases out of 35 $(80 \%)$ with discrepancies in seven cases $(20 \%)$. In two cases the EMG was graded higher than histology, and in five cases histology was graded higher than EMG. Thus the shift was not of statistical significance. Therefore, it can be concluded that reasonable correlation exists between the histological and electromyographic findings.

Table Correlation between histology and EMG

\begin{tabular}{llllll}
\hline & \multicolumn{5}{c}{ EMG grading } \\
\cline { 3 - 6 } Grading & Histology & $I$ & $I I$ & III & IV \\
\hline Grade I & 12 & $I 0$ & 2 & - & - \\
Grade II & 5 & - & 5 & - & - \\
Grade III & 7 & - & 2 & 5 & - \\
Grade IV & & - & 2 & 1 & 8 \\
\hline
\end{tabular}

Total number 35 ; grading agreement exists in 28 cases $(80 \%)$.

Discrepancies exist in seven cases $(20 \%$ ) (in two cases EMG graded higher than histology, and in five cases histology graded higher than EMG).

Conclusion: shift not significant (according to sign test).

These results can be compared with those reported by Samii et al. (1971) where an experimental study was carried out comparing autografts with different types of nerve homografts in rabbits but the length of the graft used was not mentioned. According to their study $75 \%$ of the animals with autogenous grafts regained normal function in comparison with $33 \%$ which had homografts. In this experiment no emphasis has 
been laid on the return of neurological function, but even in $70 \mathrm{~mm}$ long preserved nerve allografts with perfect tissue compatibility, a normal pattern of regeneration was found in about the same percentage of cases.

\section{References}

Ceppelini, R., Curtoni, E. S., Maltiuz, P. Z., Miggiano, V., Seudeller, G., and Serr, A. (1967). Genetics of Leukocyte Antigens. Histocompatibility Testing. p. 149, Munksgaard: Copenhagen.

Das Gupta, T. K. (1967). Mechanisms of rejection of peripheral nerve allografts. Surgery, Gynecology and Obstetrics, 125, 1058-1068.

Ducker, B., and Hayes, G. J. (1970). Peripheral nerve grafts; experimental studies in the dog and chimpanzee to define homograft limitations. Journal of Neurosurgery, 31, 236-243.

Gutmann, E., and Sanders, F. K. (1943). Recovery of fibre numbers and diameters in the regeneration of peripheral nerves. Journal of Physiology, 101, 489. 518.

Marmor, L. (1964). Regeneration of peripheral nerves by irradiated homografts. Journal of Bone and Joint Surgery, 46A, 383-394.

Marmor, L. (1967). Peripheral Nerve Regeneration using Nerve Grafts. Charles C. Thomas: Springfield, Illinois.

Millesi, H. (1972). The interfascicular nerve-grafting of the median and ulnar nerves. Journal of Bone and Joint Surgery, 54A, 727-750.
Pollard, J. D., and Fitzpatrick, L. (1973). A comparison of the effects of irradiation and immunosuppressive agents on regeneration through peripheral nerve allografts: an ultrastructural study. Acta Neuropathologica (Berlin), 23, 166-180.

Pollard, J. D., Mcleod, J. G., and Gye, R. S. (1973). Regeneration through peripheral nerve allografts. An electrophysiological and histological study following the use of immunosuppressive therapy. Archives of Neurology (Chicago), 28, 31-37.

Samii, M., and Kahl, R. L. (1972). Klinische Resultate der autologen Nerventransplantation. Melsungen Medizinisch Mitteilungen, 46, 197-202.

Samii, M., Schurmann, K., Scheinpflug, W., and Wallenborn, R. (1971). Experimental studies comparing grafting with autogenous and irradiated freeze dried homologous nerves. Proceedings of the German Society for Neurosurgery, 22nd Annual Meeting Dusseldorf. November 14-17. Excerpta Medica: Amsterdam.

Seddon, H. J., and Holmes, W. (1944). Late condition of nerve homografts in man. Surgery, Gynecology and Obstetrics, 79, 342-351.

Spurling, R. G., Lyons, W. R., Whitcomb, B. B., and Woodhall, B. (1945). Failure of whole homogenous nerve grafts in man. Journal of Neurosurgery, 2, 79-101.

Sunderland, S. (1968). Nerves and Nerve Injuries. pages 26 and 702. Churchill Livingstone: Edinburgh and London.

Wilcoxon, P. (1973). In Statistical Methods in Medical Research. Edited by P. Armitage. p. 398. Blackwell: Oxford. 